\title{
Balanço de Carbono do processo de produção de madeira de reflorestamento no Norte de Minas Gerais
}

\author{
Ciro Lacerda Souza ${ }^{1}$, Stanley Schettino ${ }^{2 *}$, Deicy Danielle Silva ${ }^{3}$, Nathália Vasconcelos Guimarães ${ }^{4}$
}

\begin{abstract}
Resumo
Este estudo objetivou avaliar o balanço das emissões e imobilizações de carbono do processo produtivo das florestas plantadas norte do Estado de Minas Gerais, tendo sido os dados coletados em áreas de plantio de Eucalyptus. Foram avaliadas todas as atividades do ciclo produtivo: silvicultura, colheita, gestão e transporte. A partir da produtividade média de cada atividade (horas-máquina por hectare) e o volume de combustível consumido por unidade de potência por hora de trabalho (litros por hora), foi calculado o consumo de combustível por atividade (litros por hectare) durante o ciclo produtivo. Para determinar a quantidade de $\mathrm{CO}_{2}$ resultante da queima do combustível adotou-se uma média de $3,2 \mathrm{~kg}$ de $\mathrm{CO}_{2}$ emitidos na atmosfera por cada litro de óleo diesel consumido e que, em termos médios, o teor de carbono presente na biomassa total seca da árvore foi de $46,3 \%$ e que uma tonelada de carbono equivale a 3,67 toneladas de $\mathrm{CO}_{2}$. Para estimar o balanço de carbono foi calculada a diferença entre o carbono imobilizado por um hectare de floresta plantada e a somatória de toda a emissão de carbono necessário para sua produção. Os resultados apontaram que foram emitidas $15,40 \mathrm{t} / \mathrm{CO}_{2}$ para produzir cada hectare de floresta e que, durante este mesmo ciclo, a floresta imobilizou 187,35 t/ $\mathrm{CO}_{2}$, representando um balanço positivo de 171,95 t/ $\mathrm{CO}_{2}$ por hectare. Assim, os reflorestamentos no norte de Minas Gerais se apresentam como alternativa para o sequestro de carbono atmosférico, contribuindo para atenuar os efeitos das mudanças climáticas.
\end{abstract}

Palavras-chave: Florestas plantadas. Sequestro de carbono. Emissões atmosféricas. Mudanças climáticas.

\section{Carbon Balance of the reforestation wood production process in Minas Gerais Northern}

\begin{abstract}
This study aimed to evaluate the carbon emissions and immobilization balance of the productive process of planted forests in the north of Minas Gerais State, Brazil, having been the data collected in Eucalyptus planting areas. All activities of the production cycle were evaluated: forestry, harvesting, management and transportation. From the average productivity of each activity (machine hours per hectare) and the volume of fuel consumed per power unit per working hour (liters per hour), the fuel consumption per activity (liters per hectare) was calculated during the productive cycle. To determine the amount of $\mathrm{CO}_{2}$ resulting from fuel combustion, an average of $3.2 \mathrm{~kg}$ of $\mathrm{CO}_{2}$ emitted into the atmosphere per liter of diesel fuel consumed was adopted and that, on average, the carbon content present in the total dry biomass of the $46.3 \%$ and one ton of carbon equals 3.67 tons of $\mathrm{CO}_{2}$. To estimate the carbon balance, the difference between the immobilized carbon per one hectare of planted forest and the sum of all carbon emissions required for its production was calculated. The results indicated that $15.40 \mathrm{t} / \mathrm{CO}_{2}$ were emitted to produce each hectare of forest and that during this same cycle the forest immobilized $187.35 \mathrm{t} / \mathrm{CO}_{2}$, representing a positive balance of $171.95 \mathrm{t} / \mathrm{CO}_{2}$ per hectare. Thus, reforestation in the Minas Gerais northern is an alternative for atmospheric carbon sequestration, contributing to mitigate the effects of climate changes.
\end{abstract}

Keywords: Planted forests. Carbon sequestration. Atmospheric emissions. Climate changes

${ }^{1}$ Universidade Federal de Minas Gerais. Campus Montes Claros. Montes Claros, MG. Brasil.

https://orcid.org/0000-0003-0222-7762

${ }^{2}$ Universidade Federal de Minas Gerais. Campus Montes Claros. Montes Claros, MG. Brasil.

https://orcid.org/0000-0001-8085-1910

${ }^{3}$ Universidade Federal de Minas Gerais. Campus Montes Claros. Montes Claros, MG. Brasil. https://orcid.org/0000-0001-8686-7999

${ }^{4}$ Universidade Federal de Minas Gerais. Campus Montes Claros. Montes Claros, MG. Brasil. https://orcid.org/0000-0001-5725-2987

*Autor para correspondência: schettino@ufmg.br

Recebido para publicação em 05 de setembro de 2019. Aceito para publicação em 06 de novembro de 2019 e-ISSN: 2447-6218 / ISSN: 2447-6218 / (C) 2009, Universidade Federal de Minas Gerais, Todos os direitos reservados. 


\section{Introdução}

A vegetação, seja ela nativa ou plantada, desempenha uma função fundamental na regulação da concentração atmosférica de gás carbônico, tudo isso em função dos processos fotossintéticos, respiração, decomposição e no consumo/produção de quantidade relevantes de $\mathrm{CO}_{2}$, que é o gás mais importante relacionado com o efeito estuda e, desta forma, com o aquecimento global. Os vegetais, utilizando-se de sua capacidade fotossintética, fixam o $\mathrm{CO}_{2}$ atmosférico, biossintetizando-o na forma de carboidratos, e por fim é depositado na parede celular, processo conhecido como "sequestro" de carbono (Carmo, 2016).

Em se tratando de florestas plantadas, o setor florestal Brasileiro conta com cerca de 8 milhões de hectares de reflorestamento, responsáveis por $91 \%$ da madeira para fins industriais e representando $6,2 \%$ do PIB Brasileiro (Ibá, 2017). Neste contexto, o cerrado tem se mostrado de grande importância no abastecimento da demanda de madeira para os mais diversos fins, a nível regional e nacional. De acordo com Lima (1997), uma das funções dos reflorestamentos em áreas de cerrado é diminuir a pressão e a necessidade de espécies nativas, preservando assim, as espécies nativas desse bioma, as quais, muitas vezes, se encontram em risco de extinção.

Entretanto, embora as atividades florestais venham apresentando importante evolução em termos técnicos, econômicos e operacionais, verifica-se que o aspecto ambiental merece maior atenção, visto que são marcantes as atividades potencialmente poluidoras por conta do porte das máquinas, caminhões, veículos de apoio, entre outros, que compõem as mais diversas atividades do ciclo de produção florestal. Os gases emitidos pelo tubo de escapamento das máquinas e veículos são constituídos pelos produtos gerados durante reação de combustão incompleta que ocorre no motor, basicamente por monóxido de carbono (CO), dióxido de carbono $\left(\mathrm{CO}_{2}\right)$, óxidos de nitrogênio $\left(\mathrm{NO}_{\mathrm{x}}\right)$ e hidrocarbonetos $(\mathrm{HC})$, que são considerados gases poluentes (Carmo, 2016).

Por outro lado, as florestas plantadas podem representar grande potencial para imobilização do carbono atmosférico. Os reflorestamentos participam do ciclo de carbono por meio da troca de $\mathrm{CO}_{2}$ com o ambiente através de processos de fotossíntese, respiração, decomposição e emissões associadas a distúrbios como fogo e à exploração florestal (Sedjo; Marland, 2003; Nascimento et al., 2011b). Sob essa ótica, é cada vez maior o interesse pela fixação de carbono em florestas plantadas, principalmente de eucalipto, devido as suas elevadas taxas de crescimento e consequente capacidade de remover dióxido de carbono da atmosfera. Tais florestas plantadas, geralmente com fins econômicos e comerciais, são orientadas por critérios técnicos, conforme um plano de manejo, definindo-se sua época de colheita. Durante sua existência, estas florestas realizam a atividade de captura e fixação de carbono na madeira e nos demais componentes (Baesso et al., 2010).
Desta forma, este estudo visou quantificar a imobilização e emissão de carbono no processo produtivo florestal para realização do balanço deste processo, em florestas plantadas no norte de Minas Gerais.

\section{Material e métodos}

\section{Caracterização da amostragem}

Os dados foram coletados em áreas de uma empresa florestal localizada nas regiões dos vales do Jequitinhonha e do São Francisco, norte do Estado de Minas Gerais, situadas entre os meridianos de $42^{\circ} 48^{\prime} 00^{\prime \prime}$ a $43^{\circ} 43^{\prime} 00^{\prime \prime}$ de longitude a Oeste de Greenwich e os paralelos de $16^{\circ} 49^{\prime} 00^{\prime \prime}$ a $17^{\circ} 42^{\prime} 00^{\prime \prime}$ de latitude a Sul da linha do Equador. A altitude onde os povoamentos se encontram variou de e $600 \mathrm{a} 1.100 \mathrm{~m}$. Todas as áreas de reflorestamento da empresa são originárias da conversão de cerrado anteriormente degradado em áreas produtivas, mediante a implantação de florestas de eucalipto.

A região do vale do Jequitinhonha abrange áreas com precipitação medial anual que vão de $750 \mathrm{~mm}$ até $1.400 \mathrm{~mm}$. Segundo a classificação climática de Köppen, os tipos climáticos predominantes na região são oAw tropical chuvoso de savana, ou seja, inverno seco e chuvas máximas no verão, e a estação chuvosa ocorre entre os meses de outubro e março (Nascimento et al., 2011a) e Cwb - temperado chuvoso e moderadamente quente, com preponderância de chuvas em verões brandamente quentes (Meira Junior et al., 2017).Já as áreas localizadas na região do vale do São Francisco, apresentam precipitação média anual variando de 760 a $1.100 \mathrm{~mm}$, com tipologia climática predominante do tipo Aw (Fonseca et al., 2016).

Nas áreas de estudo, as florestas são, em sua totalidade, cultivadas com eucaliptos em povoamentos de clones híbridos (Eucalyptus urophilla $\mathrm{x}$ E. grandis) com volume médio de $245 \mathrm{~m}^{3} / \mathrm{ha}$, em regime de alto fuste com rotação de 7 anos de idade, espaçamento 3 x $3 \mathrm{~m} \mathrm{e}$ percentual médio de sobrevivência de $95 \%$ após o plantio, com um volume médio de $0,2322 \mathrm{~m}^{3} /$ árvore e densidade básica média da madeira de $450 \mathrm{~g} / \mathrm{cm}^{3}$ (ou $0,45 \mathrm{t} / \mathrm{m}^{3}$ ), ambos aos 7 anos de idade. A colheita, por sua vez, era realizada através do sistema de árvores inteiras (full-tree), sistema em que, de acordo com Malinovski et al. (2014), a árvore é derrubada e levada para a margem da estrada ou pátio intermediário, onde é processada em pequenas toras, com comprimento menor que $6 \mathrm{~m}$. No caso deste estudo, a madeira era processada em toras com $3 \mathrm{~m}$ de comprimento.

De posse dos valores médios de Inventário Florestal, dos rendimentos médios de cada atividade e dos respectivos consumos de combustível, utilizando-se o software Excel, foram calculados todos os parâmetros necessários ao desenvolvimento deste estudo, visando 
Balanço de Carbono do processo de produção de madeira de reflorestamento no Norte de Minas Gerais

quantificar as imobilizações e emissões de carbono, bem como o seu balanço. Como não havia nenhuma hipótese a ser testada, não foi realizada nenhuma análise estatística.

\section{Atividades avaliadas}

Foram avaliadas todas as atividades presentes no ciclo de produção de madeira de florestas plantadas no norte do Estado de Minas Gerais (Imagem 1), sendo:

a) Silvicultura: abertura de aceiros, limpeza de área, subsolagem, plantio mecanizado, irrigação, adubação de cobertura, aplicação de herbicida, combate a formigas e proteção florestal;

b) Colheita: construção de estradas, manutenção de estradas, corte, extração, processamento, carregamento e manutenção mecânica;

c) Gestão: Inventário florestal e gestão florestal.

d) Transporte: Transporte pessoal e transporte de madeira.

Imagem 1 - Descrição das atividades analisadas

\begin{tabular}{|c|c|}
\hline Atividades & Caracterização da atividade \\
\hline Abertura de aceiros & $\begin{array}{l}\text { Capina de uma faixa nas margens das áreas plantadas (aproximadamente } 4 \text { metros de } \\
\text { largura) para maior proteção contra incêndios. Realizado com trator de esteiras. }\end{array}$ \\
\hline Limpeza de área & $\begin{array}{l}\text { Operações que consistem na retirada da vegetação e na mobilização do solo visando a } \\
\text { melhoria das condições do terreno para um melhor desenvolvimento da espécie }\end{array}$ \\
\hline Subsolagem & $\begin{array}{l}\text { Prática que consiste em revolver o solo através do subsolador que mobiliza o solo em } \\
\text { profundidade por hastes rompendo camadas de solo compactado. }\end{array}$ \\
\hline Plantio mecanizado & $\begin{array}{l}\text { Utiliza-se, normalmente, as plantadoras onde será feito de modo mecanizado o sulca- } \\
\text { mento, distribuição de adubo e o plantio é efetivado. }\end{array}$ \\
\hline Irrigação & Fornecimento de água ao solo de forma artificial e controlada. \\
\hline Adubação de cc & $\begin{array}{l}\text { Adubação feita após o plantio das espécies visando a manutenção dos níveis de nutrien- } \\
\text { tes do solo durante o desenvolvimento do vegetal. }\end{array}$ \\
\hline Aplic & Aplicação de substancia química visando a erradicação de plantas e ervas daninhas. \\
\hline Combate a formigas & $\begin{array}{l}\text { Conjuntos de técnicas de combate visando diminuir a população de formigas a um nível } \\
\text { aceitável ou a um nível em que não haja dano econômico. }\end{array}$ \\
\hline Construção de estradas & $\begin{array}{l}\text { Abertura do leito da estrada com trator de esteiras, regularização do leito da estrada } \\
\text { com moto niveladora, aplicação de cascalho e compactação com rolo compressor, esca- } \\
\text { vações para escoamento da água pluvial com retroescavadeira }\end{array}$ \\
\hline Manutenção de & $\begin{array}{l}\text { Regularização do leito da estrada com moto niveladora, aplicação de cascalho e com- } \\
\text { pactação com rolo compressor, escavações para escoamento da água pluvial com re- } \\
\text { troescavadeira. }\end{array}$ \\
\hline Corte & Operação que consiste na derrubada de árvores. \\
\hline Extração & $\begin{array}{l}\text { Consiste na transferência de material lenhoso do local de abate até o local de carrega- } \\
\text { mento. Operação muito diversificada tanto nos meios como nas técnicas utilizadas. }\end{array}$ \\
\hline Processamento & $\begin{array}{l}\text { Operação florestal que visa concretizar o processo de abate, corte de ramos, traçamento, } \\
\text { descascamento (quando for o caso) e empilhamento. }\end{array}$ \\
\hline Carregamento & $\begin{array}{l}\text { Visa movimentar a madeira desde as pilhas de estocagem até os caminhões que execu- } \\
\text { tarão o transporte da mesma. É executada por carregadores florestais de esteiras. }\end{array}$ \\
\hline Manutenção mecânica & $\begin{array}{l}\text { São operações de manutenção em máquinas e implementos da silvicultura e colheita } \\
\text { florestal visando falhas mecânicas juntamente com o abastecimento de todo o maquiná- } \\
\text { rio. }\end{array}$ \\
\hline Inventário florestal & $\begin{array}{l}\text { Procedimento que visa obter informações sobre as características qualitativas e quanti- } \\
\text { tativas da floresta. }\end{array}$ \\
\hline Proteção florestal & $\begin{array}{l}\text { Prática onde é realizado um plano para a proteção florestal e é feito um calendário com } \\
\text { as visitas periódicas e medidas a serem tomada quanto a ocorrência de agentes danosos. } \\
\text { Também, medidas de segurança e de combate para lidar com os incêndios florestais e } \\
\text { com sua precaução. }\end{array}$ \\
\hline
\end{tabular}


Souza, C. L. et al.

Gestão florestal

Transporte de madeira
É um plano visando a programação espacial e temporal de uma série de ações visando desenvolver, sobre vários aspectos da floresta, a sua sustentabilidade econômica, ambiental e social de forma conjunta.

Operação que consiste no deslocamento da madeira desde a floresta até as unidades consumidoras de madeira

\section{Determinação do consumo de combustível por ati- vidade}

A determinação do consumo de combustível por atividade foi a partir da produtividade média de cada atividade (horas de máquina por hectare) e o volume de combustível consumido por unidade de potência por hora de trabalho (litros por hora) o que, por relação direta, permitiu a obtenção do consumo de combustível por atividade (litros por hectare) durante o ciclo de produção da madeira.

Para cada atividade avaliada, foram tomados como base os rendimentos operacionais padrões de uma empresa florestal, por meio de estudos de tempos e movimentos com o uso do método de tempos contínuos (Barnes, 1977), de forma a determinar as horas de máquina necessárias para sua realização, ou seja, a produtividade média de cada atividade.

O consumo de combustível por máquina foi calculado com base na metodologia proposta pela ASAE American Society of Agricultural Engineers (Asae, 1989; ASae, 1996). Para veículos de transporte (caminhões, ônibus e utilitários) foram utilizados dados de controles de abastecimentos, disponibilizados pela empresa.

De acordo com as práticas usuais de manejo florestal na região do estudo, a atividade de abertura de aceiros é realizada anualmente, ou seja, em seis momentos até o corte da madeira. Por sua vez, as atividades de aplicação de herbicidas (capina química), adubação, irrigação e controle de formigas são realizadas 3 vezes cada durante o período de 7 anos. Para o transporte de madeira foi considerada uma distância média de 50 $\mathrm{km}$, desde as florestas até as unidades consumidoras da madeira.

\section{Determinação do balanço de carbono}

De forma a determinar o estoque de carbono imobilizado pelas florestas, assumiu-se que, em termos médios, o teor de carbono presente na biomassa total seca da árvore foi de 46,3\% (SILVA et al., 2015). Para a realização das análises foi feita a conversão das estimativas de carbono para $\mathrm{CO}_{2}$ equivalente. Para tanto, de acordo com Face (1994), foi assumido que uma tonelada de carbono equivale a 3,67 toneladas de $\mathrm{CO}_{2}$, ou que uma tonelada de $\mathrm{CO}_{2}$ equivaleria a 0,27 tonelada de carbono.

A etapa seguinte foi determinar a quantidade de $\mathrm{CO}_{2}$ resultante da queima do combustível necessário ao processo de produção florestal. Durante o processo de combustão, para cada litro de óleo diesel queimado, incluindo as fases de produção e distribuição desse combustível, adotou-se que são emitidos uma média de 3,2 $\mathrm{kg}$ de $\mathrm{CO}_{2}\left(0,0032\right.$ t de $\left.\mathrm{CO}_{2}\right)$ na atmosfera, conforme os estudos apresentados por Carvalho (2011).

Para a estimativa do balanço de carbono foi calculada a diferença entre o carbono imobilizado por um hectare de floresta plantada, durante o ciclo de produção de 7 (sete) anos e considerando o volume de madeira médio por hectare, e a somatória de toda a emissão de carbono necessário para sua produção durante o mesmo ciclo.

\section{Resultados e discussão}

Os resultados da determinação do consumo de combustível por atividade, necessário para a produção de 1 hectare de floresta de eucalipto, nas condições avaliadas e considerando um ciclo de 7 anos, encontram-se na Tabela 1. Dessa forma, para a produção de 1 hectare de floresta de eucalipto na região norte do Estado de Minas Gerais, são necessários 4.813,65 litros de óleo diesel, equivalentes a $15,40 \mathrm{t}$ de $\mathrm{CO}_{2}$ emitidos na atmosfera por hectare produzido (15,40 t CO2/ha). É importante ressaltar que, considerando a atividade de colheita de madeira, não existe diferença significativa de consumo de combustível (litros por hectare) com a variação da produtividade das florestas, conforme apresentado por Simões et al. (2014), mesmo comportamento verificado para as demais atividades necessárias a produção florestal.

Embora tenha sido observada uma grande evolução nos processos florestais nos últimos tempos, as operações mecanizadas ainda necessitam de alguns avanços tendo em vista o custo operacional elevado das máquinas e os impactos ambientais que podem ser causados. De acordo com Laschi et al. (2016) é necessário identificar e quantificar os danos ambientais que são causados pela atividade florestal e desta forma, será possível tomar medidas para a sustentabilidade ambiental. Destaca-se nesse contexto, as emissões dos gases da combustão dos combustíveis fósseis.

Ao avaliar o funcionamento das máquinas florestais, tem-se que a combustão nos motores vai gerar potência e gases nocivos (Teixeira et al., 2008). Os principais compostos nocivos são o gás carbônico $\left(\mathrm{CO}_{2}\right)$, o monóxido de carbono (CO), os hidrocarbonetos (HC), os óxidos de nitrogênio $\left(\mathrm{NO}_{\mathrm{X}}\right)$, os óxidos de enxofre $\left(\mathrm{SO}_{\mathrm{X}}\right)$, além de material particulado (MP), dentre outros (Braun et al., 2004). 
Balanço de Carbono do processo de produção de madeira de reflorestamento no Norte de Minas Gerais

Para IPCC (2018), a concentração atmosférica de dióxido de carbono $\left(\mathrm{CO}_{2}\right)$ vem aumentando drasticamente desde o século XVIII e aproximadamente 75\% das emissões antropogênicas de $\mathrm{CO}_{2}$ para atmosfera durante os últimos anos do século XX foram devido à queima de combustíveis fósseis, derivados do petróleo. Os outros $25 \%$ foram devido a alterações no uso da terra, especialmente relacionadas ao desmatamento.
Se por um lado as emissões atmosféricas de gases do efeito estufa possuem efeito negativo, quando a florestas são conservadas, preservadas, recuperadas ou plantadas, ocorre um processo inverso, devido ao surgimento de um sumidouro de carbono, uma vez que as florestas removem parte do $\mathrm{CO}_{2}$ da atmosfera por meio do processo de fotossíntese, promovendo o chamando sequestro de carbono (JACOVINE et al., 2008).

Tabela 1 - Produtividade média (PM, em horas máquina por hectare), consumo (CC, em litros por hora máquina) e gasto de combustível (GC, em litros por hectare) das atividades avaliadas para a produção de 1,0 hectare de floresta de eucalipto

\begin{tabular}{|c|c|c|c|c|c|c|}
\hline \multirow{2}{*}{ Atividades } & \multirow{2}{*}{$\begin{array}{l}\text { Tipo de Máquina } \\
\text { (ou Veículo) }\end{array}$} & \multirow{2}{*}{$\begin{array}{c}\mathrm{PM} \\
\text { (hm/ha) }\end{array}$} & \multirow{2}{*}{$\begin{array}{l}\text { CC (1/ } \\
\text { hm) }\end{array}$} & \multicolumn{3}{|c|}{ GC (1/ha) } \\
\hline & & & & Unit. & Repetições $^{1 /}$ & Total \\
\hline Abertura de aceiros & Trator de esteiras D6 & 1,65 & 22,00 & 36,30 & 6 & 217,80 \\
\hline Limpeza de área & Trator pneus $140 \mathrm{CV}$ & 1,10 & 25,00 & 27,50 & 1 & 27,50 \\
\hline Subsolagem & Trator pneus $180 \mathrm{CV}$ & 1,35 & 32,30 & 43,60 & 1 & 43,60 \\
\hline Plantio mecanizado & Trator pneus $140 \mathrm{CV}$ & 2,00 & 25,00 & 50,00 & 1 & 50,00 \\
\hline Irrigação & Trator pneus $110 \mathrm{CV}$ & 0,95 & 19,80 & 18,80 & 3 & 56,40 \\
\hline Adubação de cobertura & Trator pneus $110 \mathrm{CV}$ & 3,00 & 19,80 & 59,40 & 3 & 178,20 \\
\hline Aplicação de herbicidas & Trator pneus $110 \mathrm{CV}$ & 1,70 & 19,80 & 33,65 & 3 & 100,95 \\
\hline Combate a formigas & Trator pneus $110 \mathrm{CV}$ & 0,75 & 19,80 & 14,85 & 3 & 44,55 \\
\hline Construção de estradas & $\begin{array}{c}\text { Trator de esteiras D6 } \\
\text { Motoniveladora } \\
\text { Rolo compressor } \\
\text { Retroescavadeira }\end{array}$ & $\begin{array}{l}3,00 \\
2,55 \\
1,90 \\
1,50 \\
\end{array}$ & $\begin{array}{c}22,00 \\
17,00 \\
7,00 \\
12,00\end{array}$ & $\begin{array}{l}66,00 \\
43,35 \\
13,30 \\
18,00\end{array}$ & $\begin{array}{l}1 \\
1 \\
1 \\
1\end{array}$ & $\begin{array}{l}66,00 \\
43,35 \\
13,30 \\
18,00\end{array}$ \\
\hline Manutenção de estradas & $\begin{array}{l}\text { Motoniveladora } \\
\text { Rolo compressor } \\
\text { Retroescavadeira } \\
\text { Caminhão } 6 \text { x } 4 \\
\end{array}$ & $\begin{array}{l}3,60 \\
2,00 \\
1,50 \\
5,00\end{array}$ & $\begin{array}{c}17,00 \\
7,00 \\
12,00 \\
15,00\end{array}$ & $\begin{array}{l}61,20 \\
14,00 \\
18,00 \\
75,00 \\
\end{array}$ & $\begin{array}{l}1 \\
1 \\
1 \\
1\end{array}$ & $\begin{array}{l}61,20 \\
14,00 \\
18,00 \\
75,00 \\
\end{array}$ \\
\hline Corte & $\begin{array}{l}\text { Feller buncher de } \\
\text { esteiras }\end{array}$ & 2,45 & 30,00 & 73,50 & 1 & 73,50 \\
\hline Extração & Skidder 6 x 6 de pneus & 4,90 & 22,00 & 107,80 & 1 & 107,80 \\
\hline Processamento & $\begin{array}{c}\text { Garra traçadora de } \\
\text { esteiras }\end{array}$ & 4,10 & 25,00 & 102,50 & 1 & 102,50 \\
\hline $\begin{array}{l}\text { Carregamento de } \\
\text { madeira }\end{array}$ & Grua de esteiras & 4,90 & 20,00 & 98,00 & 1 & 98,00 \\
\hline Manutenção mecânica & $\begin{array}{c}\text { Caminhão comboio } \\
\text { Caminhão oficina } \\
\text { Utilitário } 4 \text { x } 4\end{array}$ & $\begin{array}{c}9,50 \\
12,75 \\
6,50\end{array}$ & $\begin{array}{l}24,00 \\
20,00 \\
15,00\end{array}$ & $\begin{array}{c}228,00 \\
255,00 \\
97,50\end{array}$ & $\begin{array}{l}1 \\
1 \\
1\end{array}$ & $\begin{array}{c}228,00 \\
255,00 \\
97,50\end{array}$ \\
\hline Inventário florestal & Utilitário 4 x 4 & 6,50 & 15,00 & 97,50 & 5 & 487,50 \\
\hline Proteção florestal & Utilitário 4 x 4 & 5,00 & 15,00 & 75,00 & 7 & 525,00 \\
\hline Gestão florestal & Utilitário 4 x 4 & 5,00 & 15,00 & 75,00 & 7 & 525,00 \\
\hline Transporte de pessoal & Ônibus & 8,35 & 13,50 & 112,70 & 6 & 676,20 \\
\hline Transporte de madeira & Caminhão bitrem & 21,78 & 28,00 & 609,80 & 1 & 609,80 \\
\hline Total & & & & & & $4.813,65$ \\
\hline
\end{tabular}

1/Referente à quantidade de vezes que a atividade é realizada durante o ciclo de 7 anos. 
Souza, C. L. et al.

Especificamente, os plantios de eucalipto, por terem um alto incremento de carbono, quando comparado a outras espécies, têm um importante papel na retirada de $\mathrm{CO}_{2}$ da atmosfera e sua fixação na superfície terrestre. Dessa forma, considerando os plantios de eucaliptos na região norte de Minas Gerais, com espaçamento de $3 \mathrm{x}$
3 metros no plantio, 95\% de sobrevivência aos 7 anos de idade, resultando em aproximadamente 1.055 árvores por hectare e um volume médio de $245 \mathrm{~m}^{3}$, a estimativa da quantidade total de $\mathrm{CO}_{2}$ imobilizado encontra-se na Tabela 2.

Tabela 2 - Estoque de CO2 (toneladas por hectare) imobilizado na biomassa aérea dos plantios de eucalipto na região norte do Estado de Minas Gerais, aos sete anos de idade

\begin{tabular}{|c|c|c|c|c|c|c|c|}
\hline Espécie & $\begin{array}{l}\text { Volume to- } \\
\text { tal (m³/ha) }\end{array}$ & $\begin{array}{c}\text { Densidade } \\
\text { básica }(t / \\
\left.m^{3}\right)\end{array}$ & $\begin{array}{l}\text { Volume de } \\
\text { matéria } \\
\text { seca }(t / h a)\end{array}$ & $\begin{array}{c}\text { \% de C na } \\
\text { biomassa } \\
\text { seca }\end{array}$ & $\begin{array}{l}\text { Estoque de } \\
\mathrm{C}(\mathrm{t} / \mathrm{ha})\end{array}$ & $\mathrm{t} \mathrm{CO}_{2} / \mathrm{t} \mathrm{C}$ & $\begin{array}{c}\text { Estoque } \mathrm{CO}_{2} \\
\text { (t/ha) }\end{array}$ \\
\hline Eucalipto & 245,00 & 0,450 & 110,25 & 46,30 & 51,05 & 3,67 & 187,35 \\
\hline
\end{tabular}

Desta forma, pela diferença entre o estoque de $\mathrm{CO}_{2}$ retirado da atmosfera $(187,35 \mathrm{t})$ e a quantidade emitida para a produção (15,40 t), estima-se que cada hectare plantado com eucalipto na região norte do Estado de Minas Gerais seja capaz de imobilizar 171,95 toneladas de $\mathrm{CO}_{2}$, contribuindo, sobremaneira, para atenuar os efeitos do aquecimento global.

A quantidade de estoque de dióxido de carbono feita pelas florestas é 12 vezes maior em comparação com as emissões feitas para a produção do ciclo florestal, isso presume um elevado potencial na regulação da concentração atmosférica de gás carbônico e assim, a redução dos gases de efeito estufa.

Paixão et al. (2006) relataram um estoque de 47,7 toneladas da parte aérea de carbono por hectare em plantios de reflorestamento, se mostrando bem próximo do presente estudo onde foi estocado 51,05 toneladas de carbono, tal diferença é justificada pelo tempo da cultura que foi respectivamente 6 e 7 anos de idade. $\mathrm{O}$ mesmo autor ainda relata a soma de 23,43 toneladas de carbono referente ao estoque nas raízes $(14,71 \mathrm{t})$ e na manta orgânica $(8,72 \mathrm{t})$, o que mostra o potencial de estoque de carbono quando se adiciona os estoques de raízes e material presentes na serapilheira. Tais valores demonstram a importância dos reflorestamentos neste contexto quando comparado ao cerrado strictu sensu, cujos valores de $\mathrm{CO}_{2}$ imobilizado variaram de 10 até aproximadamente 37 toneladas por hectare (Aduan et al., 2003; Fernandes et al., 2008; Lopes; Miola, 2010), lembrando que no cerrado é necessário que haja a queima prévia da vegetação (liberação de $\mathrm{CO}_{2}$ ) para que haja a posterior regeneração e, novamente, sua imobilização.

Sang et al. (2013), comparando plantações de Acacia mangium e Eucalyptus urophylla, florestas secundárias e pastagens em gradientes de solo e clima, concluíram que o reflorestamento adequado melhora a fertilidade do solo e promove o sequestro de carbono em terras tropicais degradadas. Desse modo, é evidente o potencial das florestas plantadas para a imobilização do carbono em áreas do norte do Estado de Minas Gerais, principalmente por conta de suas elevadas taxas de crescimentos iniciais junto com sua eficácia em remover o dióxido de carbono de atmosfera, na qual se destaca o eucalipto.

Muito embora os resultados positivos do sequestro de Carbono pelas florestas sejam notadamente importantes, Chang (2011) afirma que as formas de sequestrar carbono florestal podem ser simplificadamente classificadas em três tipos, quais sejam: a preservação do estoque de carbono nas florestas já existentes através de ação protetora; o aumento do estoque de carbono florestal por meio de uma ação combinada de práticas de manejo florestal sustentável, regeneração florestal e reflorestamento em áreas degradadas, ou introdução de atividades agroflorestais em áreas de agricultura; e a substituição de combustíveis fósseis por produtos de biomassa vegetal sustentáveis.

Mesmo assim, o manejo adequado do solo e da vegetação deve ter como premissa básica a utilização de métodos com o mínimo revolvimento do solo, assim como os sistemas de rotação e sucessão de culturas que incluam plantas com alta produção de resíduos vegetais e, ainda, plantas capazes de acumular nutrientes no solo, lembrando que, ainda, devem ser preservadas as vegetações nativas remanescentes, bem como realizar plantios de reflorestamento em larga escala, pois nesses ambientes estão as maiores quantidades de carbono sequestradas no sistema solo-planta (Nunes Carvalho et al., 2010).

Em uma abordagem de curto e médio prazos, Baesso et al. (2010) concluem, a partir de simulações, que em uma projeção de 2011 até 2040 o eucalipto tende a fixar mais carbono num futuro próximo, isso por conta de um maior índice de produção de matéria seca, elevando o potencial de imobilização de dióxido de carbono por parte do eucalipto e também torna viável, ainda mais, projetos de reflorestamentos ligados à venda de créditos de carbono tornando, desta forma, o empreendimento economicamente atraente.

Ainda, de acordo com Oliveira; Oliveira (2017), vale ressaltar que o potencial de solos florestais de estocar carbono depende, principalmente, do uso apropriado da terra, de técnicas adequadas de fertilizações, práticas conservacionistas e a conversão de áreas degradadas, 
Balanço de Carbono do processo de produção de madeira de reflorestamento no Norte de Minas Gerais

as quais, isolada ou conjuntamente, podem ser grandes aliados no combate à mudança do clima. Em plantios de reflorestamento na região norte de Minas Gerais, tais práticas vêm sendo amplamente utilizadas, contribuindo grandemente para o desenvolvimento socioambiental da região.

\section{Conclusão}

Nas condições em que este estudo foi realizado, é possível concluir que:

- $\quad$ Para a produção de florestas plantadas na região norte do Estado de Minas Gerais, considerando um ciclo de 7 anos e todas as atividades desde o plantio até o transporte da madeira, são emitidas $15,40 \mathrm{t} / \mathrm{CO}_{2}$ por hectare.

- Cada hectare de floresta plantada, durante este mesmo ciclo, imobiliza 187,35 t/ $\mathrm{CO}_{2}$.

- Esses valores de emissão e imobilização representam um balanço positivo de $171,95 \mathrm{t} / \mathrm{CO}_{2}$ por hectare.

- Os reflorestamentos do norte de Minas Gerais se apresentam como alternativa para o sequestro de carbono da atmosfera, contribuindo para atenuar os efeitos indesejáveis das emissões de $\mathrm{CO}_{2}$.

\section{Referências}

Aduan, R. E.; Vilela, M. D. F; Klink, C. A. 2003. Ciclagem de carbono em ecossistemas terrestres: o caso do cerrado brasileiro. Embrapa Cerrados, Brasília, DF, Brasil (Documentos INFOTECA-E). Disponível em: https://bit.ly/2koUwmJ.

American Society of Agricultural Engineers - ASAE. 1989. Agricultural tractor test code. In: ASAE standards 1989: standards engineering practices data (ASAE S-209.5). St. Joseph, MO, USA.

American Society of Agricultural Engineers - ASAE. 1996. Agricultural machinery management data. In: ASAE standards 1996: standards engineering practices data (ASAE D-497.2). St. Joseph, MO, USA.

Baesso, R. C. E.; Reis, M. G.; Ribeiro, A; Silva, M. P. 2010. Balanço de Carbono em Floresta de Eucalipto. Anais do Congresso Brasileiro de Meteorologia, Belém, PA, Brasil, 16. Disponível em: http://www.sbmet. org.br/cbmet2010/artigos/393_92666.pdf.

Barnes, R.M. 1977. Estudo de movimentos e de tempos: projeto e medida do trabalho. Edgard Blücher, São Paulo.

Braun, S; Appel, L. G.; Schmal, M. 2004. A poluição gerada por máquinas de combustão interna movidas à diesel - a questão dos particulados. Estratégias atuais para a redução e controle das emissões e tendências futuras. Química Nova, 27, 472-482. Disponível em: http://www.scielo. br/pdf/\%0D/qn/v27n3/20176.pdf.

Carmo, F. C. A. 2016. Balanço da emissão de gases carbônicos nas operações florestais e sequestro de carbono em florestas plantadas no Espírito Santo. Jerônimo Monteiro: Universidade Federal do Espírito Santo, 68p. Tese Doutorado. Disponível em: http://repositorio.ufes. br/handle/10/7702.

Carvalho, C.H.R. 2011. Emissões relativas de poluentes do transporte motorizado de passageiros nos grandes centros urbanos brasileiros. Instituto de Pesquisa Econômica Aplicada (IPEA), São Paulo. Disponível em: https://bit.ly/2krxnzX.

Chang, M. 2011. Sequestro de carbono florestal: oportunidades e riscos para o Brasil. Revista Paranaense de Desenvolvimento, 102, 85-101. Disponível em: https://bit.ly/2k0nh9a.

Fernandes, A.; Salis, S. M.; Fernandes, F.; Crispim, S. 2008. Estoques de carbono do estrato arbóreo de Cerrados no pantanal da Nhecolândia. Embrapa Pantanal, Corumbá, MS, Brasil (Documentos INFOTECA-E). Disponível em: https://bit.ly/2ls3zn3.
Fonseca, S. F; Souza, M. J. H.; Silva, A. C. 2016. Análise da precipitação pluviométrica do município de Pirapora-MG (1961 e 2013). Revista Ra'e Ga, 38, 35-49. Disponível em: https://bit.ly/328HZV3.

Forest Absorbing Carbon Dioxide Emission Foundation - FACE. 1994. Annual Report 1993. FACE, Arnheim, Netherlands.

Indústria Brasileira de Árvores - IBÁ. 2017. Anuário IBÁ 2017: ano base 2016. Pöyry Consultoria em Gestão e Negócios Ltda, Brasília, DF, Brasil. Disponível em: https://bit.ly/2zJ3QXn.

Intergovernmental Panel on Climate Change - IPCC. 2018. A report of working Group I of the intergovernmental panel on climate change. IPCC, Genebra, Suíça. Disponível em: https://bit.ly/2lu81lm.

Jacovine, L. A. G.; Soares, C. P. B.; Ribeiro, S. C.; Silva, R. F; Paixão, F. A. 2008. Sequestro de carbono em povoamentos florestais de eucalipto e a geração de créditos de carbono. Informe Agropecuário, 29, 90-104. Disponível em: https://bit.ly/2krZj6L.

Laschi, A.; Marchi, E.; García, S. G. 2016. Forest operations in coppice: Environmental assessment of two different logging methods. Science of the Total Environment, 562, 493-503. Disponível em: https://doi. org/10.1016/j.scitotenv.2016.04.041.

Lima, D.G. 1997. Importância das florestas plantadas como forma de reduzir a pressão sobre as florestas nativas ainda existentes. Revista Bahia Agrícola, 1, 45-48. Disponível em: https://bit.ly/2lv90qc.

Lopes, R. B.; Miola, D. T. B. 2010. Sequestro de carbono em diferentes fitofisionomias do cerrado. Revista Digital FAPAM, 2, 127-143. Disponível em: https://bit.ly/2ltlcD9.

Malinovski, J. R.; Camargo, C. M. S.; Malinovski, R. A. 2014. Sistemas. p. 178-205. In: Machado, C.C. (Ed.). Colheita Florestal. Editora UFV, Viçosa, MG, Brasil.

Meira Junior, M. S. D.; Pereira, I. M.; Machado, E. L. M.; Mota, S. D. L.; Ribeiro, P. S. S. D. P; Otoni, T. J. O. 2017. Impacto do fogo em campo sujo no Parque Estadual do Biribiri, Minas Gerais, Brasil. Floresta e Ambiente, 24, e00110814. Disponível em: https://bit.ly/2jUKauw.

Nascimento, A. C.; Leite, A. M. P.; Soares, T. S.; Freitas, L. D. 2011 a. Avaliação técnica e econômica da colheita florestal com feller buncher. Cerne, 17, 9-15. Disponível em: https://bit.ly/2lBLumr. 
Souza, C. L. et al.

Nascimento, J. J. V. R.; Paula, R. R.; Da Silva, G. F.; Pereira, R. G.; Neto, F. B. 2011b. Balanço de carbono, aquecimento global e recuperação áreas degradadas. Revista Verde de Agroecologia e Desenvolvimento Sustentável, 6, 14-29. Disponível em: https://bit.ly/2jWhAJd.

Nunes Carvalho, J. L.; Avanzi, J. C.; Naves Silva, M. L.; Mello, C. R. D.; Pellegrino Cerri, C. E. 2010. Potencial de sequestro de carbono em diferentes biomas do Brasil. Revista Brasileira de Ciência do Solo, 34, 277-290. Disponível em: https://bit.ly/2kfT0U4.

Oliveira, Y. M. M.; Oliveira, E. B. 2017. Plantações florestais: geração de benefícios com baixo impacto ambiental. Embrapa Florestas, Brasília, DF, Brasil. Disponível em: https://bit.ly/2ks3Tlt.

Paixão, F. A.; Soares, C. P. B.; Jacovine, L. A. G.; Silva, M. D.; Leite, H. G.; Silva, G. D. 2006. Quantificação do estoque de carbono e avaliação econômica de diferentes alternativas de manejo em um plantio de eucalipto. Revista Árvore, 30, 411-420. Disponível em: https://bit. ly/2jUMiCw.
Sang, P. M.; Lamb, D.; Bonner, M.; Schmidt, S. 2013. Carbon sequestration and soil fertility of tropical tree plantations and secondary forest established on degraded land. Plant and Soil, 362, 187-200. Disponível em: https://doi.org/10.1007/s11104-012-1281-9.

Sedjo, R. A., Marland, G. 2003. Inter-trading permanent emissions credits and rented temporary carbon emissions offsets: some issues and alternatives. Climate Policy, 3, 435-444. Disponível em: https:// doi.org/10.1016/S1469-3062(03)00051-2.

Silva, C. A.; Klauberg, C.; Carvalho, S. P. C.; Piccolo, M. C.; Rodriguesz, L. C. E. 2015. Estoque de carbono na biomassa aérea florestal em plantações comerciais de Eucalyptus spp. Scientia Forestalis, 43, 135146. Disponível em: https://bit.ly/21A58iG.

Simões, D.; Fenner, P. T.; Esperancini, M. S. T. 2014. Produtividade e custos do feller-buncher e processador florestal em povoamento de eucalipto de primeiro corte. Ciência Florestal, 24, 621-630. Disponível em: https://bit.ly/36zgxSU.

Teixeira, E. C.; Feltes, S.; Santana, E. R. R. 2008. Estudo das emissões de fontes moveis na Região Metropolitana de Porto Alegre, Rio Grande do Sul. Revista Química Nova, 31, 244-248. Disponível em: https:// bit.ly/2lRp6Wl. 